\title{
Coagulation factor concentrate in the treatment of the haemorrhagic diathesis of fulminant hepatic failure
}

\author{
B. G. GAZZARD, M. L. LEWIS, G. ASH, C. R. RIZZA, E. BIDWELL, \\ AND ROGER WILLIAMS
}

From the Liver Unit and Department of Haematology, King's College Hospital and Medical School, London and the Plasma Fractionation Laboratory and Oxford Haemophilia Centre, Churchill Hospital, Oxford

SUMMARY To assess the value of clotting factor concentrate infusions in fulminant hepatic failure, a controlled trial was performed in which nine patients were randomly allocated to treatment with either concentrate alone or concentrate plus heparin. The five patients receiving concentrate alone all died, with major bleeding as the direct cause of death in three, whereas in the four receiving heparin as well there was only one instance of bleeding and one patient survived. Clinical evidence of intravascular coagulation appeared in two patients treated with concentrate alone and the laboratory evidence of this progressed during the period of infusions in all patients in both treatment groups, although to a lesser extent in those receiving heparin. Additional evidence for intravascular coagulation came from the changes observed in factor VIII levels which, although initially high in all patients, fell subsequently, particularly in those given concentrate alone.

There was some improvement in the prothrombin ratio in both groups of patients but not complete correction, and serial assays of clotting factors showed that although factor II rose to high levels during treatment, factors IX and X showed little response. Thus, the use of concentrate of factor IX in this trial, as well as potentiating intravascular coagulation, was inadequate as replacement for the clotting factor deficiencies.

A severe coagulation disturbance is a characteristic feature of the clinical syndrome of fulminant hepatic failure and in a recent series bleeding was the principal cause of death in $35 \%$ of the patients (Clark, Rake, Flute, and Williams, 1973). Levels of clotting factors II, V, VII, IX, and X are all reduced, as well as that of antithrombin III, partly because of a failure of hepatic synthesis and partly by increased consumption as a result of intravascular coagulation (Rake, Shilkin, Flute, Lewis, Winch, and Williams, 1971). To make up for the defect in hepatic synthesis, fresh frozen plasma is infused and in severe cases heparin has often been given as well to control intravascular coagulation. The frequency of severe bleeding may be reduced by these measures and we now routinely start infusions of fresh frozen plasma in all patients with fulminant hepatic failure, as soon as they are admitted to hospital. The amount of fresh frozen plasma needed, however, can represent a considerable load of both water and sodium to these patients whose renal excretion is Received for publication 7 August 1974. often impaired. With concentrates of coagulation factors this problem does not occur.

In this paper we describe the results of prophylactic correction of the clotting factor deficiency in fulminarit hepatic failure, obtained with a new preparation of factor IX which also contains factors $\mathrm{X}$ and Il, and a variable but small amount of factor VII (Dike, Bidwell, and Rizza, 1972). Two groups of patients were treated, one receiving concentrates alone and the other heparin as well.

\section{Patients and Methods}

The trial was originally planned to include 10 patients randomly allocated to the two groups, but after nine consecutive admissions (five in group $A$ who received concentrate alone, and four in group B who also received heparin) the trial was stopped for reasons which will be apparent later. All the patients had evidence of hepatic encephalopathy on admission and in each instance the prothrombin time ratio was greater than $2 \cdot 2$ (table). 


\begin{tabular}{|c|c|c|c|c|c|}
\hline Case & $\begin{array}{l}\text { Age } \\
(y r)\end{array}$ & Aetiology & $\begin{array}{l}\text { Coma Grade } \\
\text { on Arrival }\end{array}$ & $\begin{array}{l}\text { Maximum } \\
\text { Serum Bilirubin } \\
(\mathrm{mg} / 100 \mathrm{ml})\end{array}$ & Haemorrhage \\
\hline $\begin{array}{l}\text { Concentrates alone } \\
1 \\
2 \\
3 \\
4 \\
5\end{array}$ & $\begin{array}{l}55 \\
26 \\
40 \\
59 \\
38\end{array}$ & $\begin{array}{l}\text { Halothane-associated } \\
\text { Acute fatty liver of pregnancy } \\
\text { Halothane-associated } \\
\text { Acute viral hepatitis } \\
\text { Paracetamol overdose }\end{array}$ & $\begin{array}{l}\text { IV } \\
\text { III } \\
\text { II } \\
\text { IV } \\
\text { I }\end{array}$ & $\begin{array}{l}29 \\
26 \\
22 \\
25 \\
10\end{array}$ & $\begin{array}{l}\text { Gastrointestinal } \\
\text { Gastrointestinal } \\
\text { Purpura, gastrointestinal } \\
\text { Retroperitoneal } \\
\text { Purpura }\end{array}$ \\
\hline $\begin{array}{l}\text { Concentrates and heparin } \\
6 \\
7 \\
8 \\
9\end{array}$ & $\begin{array}{l}40 \\
55 \\
42 \\
46\end{array}$ & $\begin{array}{l}\text { Paracetamol overdose } \\
\text { Halothane-associated } \\
\text { Acute viral hepatitis } \\
\text { Acute viral hepatitis }\end{array}$ & $\begin{array}{l}\text { II } \\
\text { IV } \\
\text { II } \\
\text { III }\end{array}$ & $\begin{array}{l}21 \\
23 \\
24 \\
35\end{array}$ & $\begin{array}{l}\text { Gastrointestinal } \\
\text { None } \\
\text { None } \\
\text { None }\end{array}$ \\
\hline
\end{tabular}

Table Relevant clinical and pathological data ${ }^{1}$

${ }^{1}$ Case 8 was the only survivor.

Each vial of the freeze-dried concentrate was assayed at the Oxford Haemophilia Centre before despatch and contained on average 930 units of factor IX, 400 units of factor X, 1450 units of factor II, but less than 25 units of factor VII. After reconstituting with $20 \mathrm{ml}$ of sterile distilled water, the concentrate was administered slowly by a syringe into a peripheral vein over a 10-minute period. This was repeated every six hours. In the group B patients heparin was given, before administration of concentrate, by constant pump infusion so as to maintain a blood level of heparin of $0.5 \mathrm{mg} / 100 \mathrm{ml}$ as assessed by titration against protamine sulphate (O'Shea, Flute, and Pannell, 1971).

Clotting factor assays were performed immediately before infusion and 30 minutes after finishing infusion of the concentrate. A two-stage assay was used for factors II, VIII, and IX, and one-stage assays for factors V and X (Biggs, 1972). Blood was stored at $-40^{\circ} \mathrm{C}$ and the factor assays were performed in batches. Where necessary, the heparin in the samples was first neutralized with a $2 \mathrm{mg} / 100 \mathrm{ml}$ solution of protamine sulphate. Other tests of clotting function were performed daily, including platelet count, prothrombin time and thrombin clotting time, the results of the latter two being expressed as a ratio with normal control (Biggs, 1972). Fibrinogen was estimated gravimetrically (Biggs, 1972). Fibrin(ogen) degradation products were detected by the tanned red cell haemagglutination inhibition technique (Merskey, Lalizari, and Johnson, 1969) and the presence of plasminogen activator by the fibrin plate method (Biggs, 1972). The presence of circulating fibrin monomer was estimated using the serial dilution protamine sulphate test (Gurewich and Hutchinson, 1971).

\section{Results}

Two of the five patients in group A had episodes of unexplained hypotension within one to two hours of the infusion of concentrate. None of the patients had evidence of bleeding before the infusions, but within 48 hours of their commencement major bleeding, as evidenced by haematemesis and melaena, had occurred in three of them. Bleeding was the major cause of death in three patients and may have contributed to it in the others, four of the deaths occurring within one week of admission and the fifth after 14 days (see table). Two of these patients were given heparin intravenously during the last 24 hours of life, as they developed widespread purpura with evidence of intravascular coagulation on laboratory testing. The main necropsy finding, in addition to extensive hepatic necrosis, was gastrointestinal haemorrhage in four patients, in two of whom pulmonary haemorrhages were also present.

One of the four patients in group B, who were given heparin in addition to concentrate, survived. The other three patients died of respiratory difficulties related to progressive hepatic encephalopathy. One patient who had been bleeding before inclusion in the trial continued to bleed to a minor degree while concentrate was being given.

The prothrombin time was considerably prolonged in all nine patients on admission to the trial, and, in some, laboratory evidence of intravascular coagulation was present, namely, a prolonged thrombin clotting time in seven, a low fibrinogen level in three (normal for our laboratory $200 \mathrm{mg} / 100 \mathrm{ml}$ ), a platelet count below $100000 / \mathrm{c} \mathrm{mm}$ in two, a positive result in the serial dilution of protamine sulphate test in two, and raised levels of fibrin(ogen) degradation products in one (fig 1). In the group A patients given concentrate alone, the abnormality of coagulation tests became more marked during treatment, and fibrinogen concentration and platelet counts fell to low levels. The serial-dilution of protamine sulphate test became positive in all patients (fig 1) and levels of fibrinogen degradation products rose further in three. This deterioration in haematological results was less marked in the group B patients 


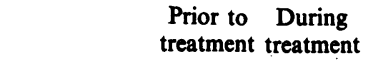

\begin{tabular}{l|ll} 
SDPS test + & 1 & 5 \\
FDP $>4 \mu \mathrm{g} / \mathrm{ml}$ & 1
\end{tabular}
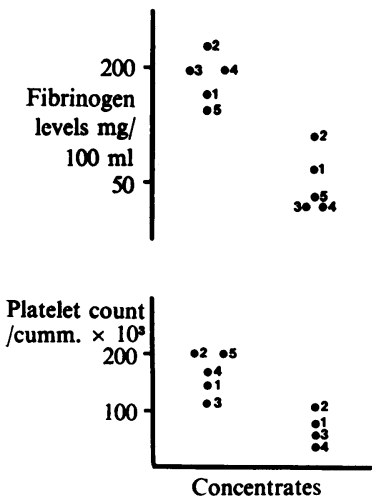

Total patients 5

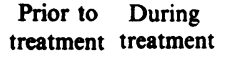

14

02

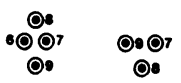

O6

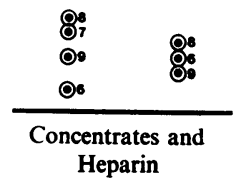

4

Fig 1 Coagulation tests on admission to the trial and during the course of the subsequent treatment period in the two groups of patients.

who received heparin in addition, the fibrinogen level falling to below $100 \mathrm{mg} / 100 \mathrm{ml}$ in only one instance.

In most cases, there was some reduction of the prothrombin time ratio following the start of treatment, but this was completely corrected in only two patients, one from each group (fig 2).

\section{INDIVIDUAL FACTOR ASSAYS}

Group $A$

In the patients given concentrate alone there was an initial rapid rise in factor II which reached levels of greater than $400 \%$ of normal in four of the five cases. In the two patients who developed purpura during the last 24 hours of life there was at this time a steep fall in the levels of factor II (fig 3). In contrast, the rise in plasma factor IX was much smaller, and in three patients the level of factor IX never rose above $30 \%$ at any time and in the other two patients only occasional levels were greater than this (fig 4).

Of the 21 factor IX assays carried out in this group immediately before and $\mathbf{3 0}$ minutes after the infusion of each vial of concentrate, there was no detectable rise in 12 instances and an increase of less than $5 \%$ on five occasions. Increases in factor $X$



Fig 2 Prothrombin time ratio before concentrate infusions and then daily during treatment in the two groups of patients. 


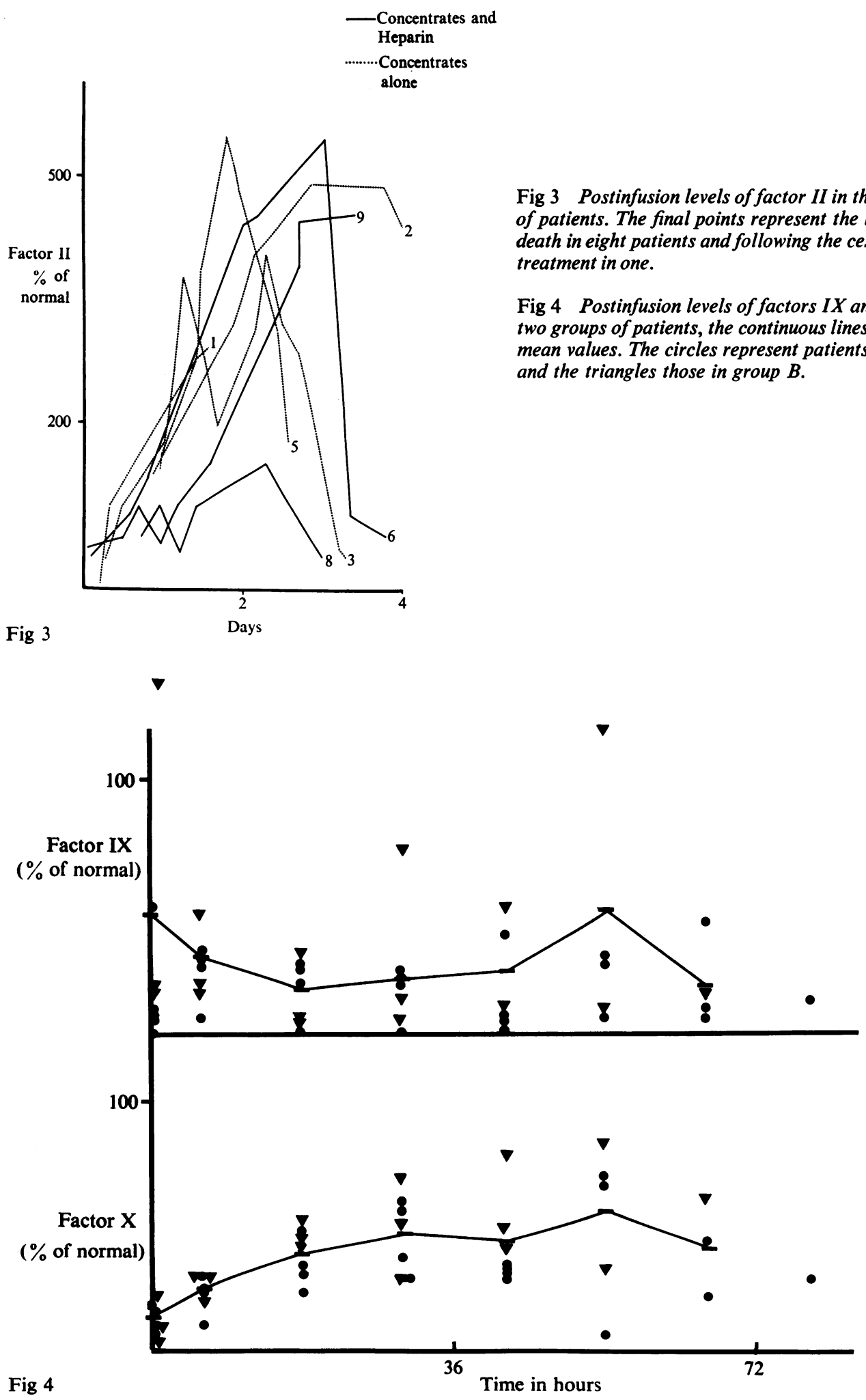




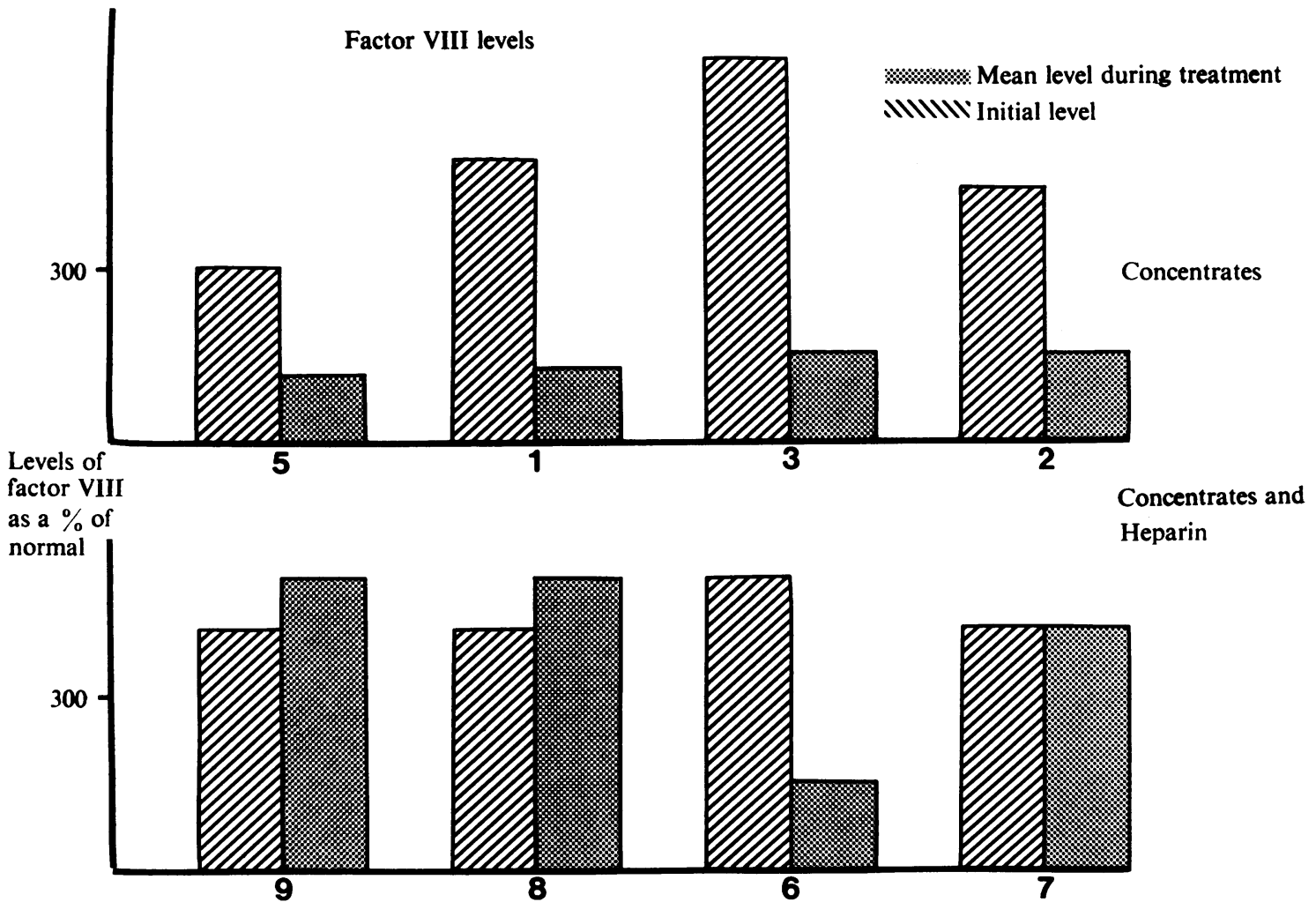

Fig 5 Levels of factor VIII before treatment and the mean postinfusion level over the treatment period in the two groups.

were also small, with four of the five patients having levels of less than $30 \%$ of normal during the major part of the treatment period (fig 4).

Although the factor VIII level was considerably elevated initially in the four cases where this was measured, it fell rapidly during the period of concentrate infusion to values of less than $100 \%$ (fig 5). In the two patients started on heparin because of the development of intravascular coagulation, the factor VIII levels rose subsequently from 25 to $100 \%$. Factor $\mathrm{V}$ levels diminished progressively to $10 \%$ or less in all five patients during the course of the illness, and in three values of $1 \%$ or less were recorded.

\section{Group B}

In the four patients treated with heparin in addition to the concentrate the changes in clotting factor assays were similar to those in group A, with considerably increased factor II levels, small changes only in factors IX and X, and low levels of factor V throughout (figs 3 and 4). A difference was observed in the factor VIII levels which did not drop in three cases during the period of infusions (fig 5). The only patient in this group who bled during the treatment period developed low levels of factor VIII and fibrinogen.

\section{Discussion}

The frequency with which bleeding developed in the group of patients treated with concentrates alone was even higher than we have seen previously in patients with fulminant hepatic failure in whom an attempt was made to correct the synthetic defect by fresh frozen plasma. There are two possible reasons for this. First, the concentrate used may have provided a less adequate replacement for the synthetic defect than fresh frozen plasma, as it does not contain factor $\mathrm{V}$ and only small amounts of factor VII. The factor V levels were considerably reduced in our patients, and although factor VII assays were not performed, it is likely that these levels were also low. Congenital deficiencies of factor V and factor VII are not associated with a severe bleeding tendency, but low levels of these 
factors may be more important when accompanied by reduced levels of other clotting factors. The levels of factor IX in our patients responded poorly to treatment and the rise with infusion of concentrate was less than in patients with Christmas disease (Biggs, 1966). Although it may have been possible to increase these levels by a higher dose regime, this would have increased the levels of factor II still further, and may possibly have aggravated the hypercoagulable state which may have been present in these patients. About a quarter of the blood samples taken by a clean venepuncture from the group given concentrate alone clotted before they could be put into citrate solution.

The second possible reason for the excessive bleeding in these patients is the development of clinically significant intravascular coagulation. The laboratory indices of intravascular coagulation became more marked in all patients during the course of the infusions and two developed purpura. These changes were less marked in the group given heparin in addition to the concentrate infusions. The dramatic drop in factor II levels, following an initial rise to high levels, also suggested that consumption of clotting factors was occurring. The fall in the factor VIII levels is even more convincing, in that it was not seen when heparin was also administered in the group B patients. In two patients in group A given heparin during the last 24 hours of life the lowering of factor VIII was partly reversed.

Why intravascular coagulation should have been potentiated in this way is uncertain, but the concentrate may contain small amounts of activated clotting factors or thrombin, and natural inhibitors of this may have been separated during the fractionation process. The Oxford concentrate, including the batches used for the patients reported in this paper, have been very successfully used in the treatment of Christmas disease without clinical evidence of intravascular coagulation, but the liver in that condition is normal and would rapidly clear small quantities of activated factors. Another possibility is that the concentrates simply provided large amounts of clotting factors, thus aggravating the intravascular coagulation known to occur in fulminant hepatic failure (Rake et al, 1971) and of which there was already some evidence in the patients before treatment.

Further work is clearly needed on the possible potentiation of the bleeding diathesis in acute hepatic failure, but for the moment the use of factor IX concentrate cannot be recommended in this condition, both because of the poor correction of the clotting factor defect and also because of the possible aggravation of intravascular coagulation.

B.G.G. was supported by the King's College Hospital Research Committee. The technical assistance of Mrs Ann Sweeney and Mrs Jackie Houston is gratefully acknowledged.

\section{References}

Biggs, R. and Macfarlane, R. G. Editors (1966). Treatment of Haemophilia and Other Coagulation Disorders. Blackwell, Oxford.

Biggs, R. Editor (1972). Human Blood Coagulation, Haemostasis and Thrombosis. Blackwell, Oxford.

Clark, R., Rake, M. O., Flute, P. T., and Williams, R. (1973). Coagulation abnormalities in acute liver failure: pathogenetic and therapeutic implications. Scand. J. Gastroent., 8, Suppl. 19, 63-70.

Dike, G. W. R., Bidwell, E., and Rizza, C. R. (1972). The preparation and clinical use of a new concentrate containing factor IX, prothrombin and factor $X$ and of a separate concentrate containing factor VII. Brit. J. Haemat., 22, 469-490.

Gurewich, V., and Hutchinson, E. (1971). Detection of intravascular coagulation by a serial-dilution protamine sulfate test. Ann. intern. Med., 75, 895-902.

Merksey, C., Lalizari, P., and Johnson, A. J. (1969). A rapid, simple, sensitive method for measuring fibrinolytic split products in human serum. Proc. Soc. exper. Biol. (N.Y.), 131, 871-875.

O'Shea, M. J., Flute, P.T., and Pannell, G.M. (1971). Laboratory control of heparin therapy. J. clin. Path., 24, 542-546.

Rake, M. O., Shilkin, K. B., Flute, P. T., Lewis, M. L., Winch, J., and Williams, R. (1971). Early and intensive therapy of intravascular coagulation in acute liver failure. Lancet, 2, 1215-1218. 